\title{
RANCANG BANGUN KONTRUKSI DAN SISTEM GERAK SUMBU PADA MESIN FUSED DEPOSITION MODELLING
}

\author{
Jeffrey, Didi Widya Utama dan Soeharsono \\ Program Studi Teknik Mesin, Fakultas Teknik Universitas Tarumanagara, Jakarta \\ e-mail: jeffrey.515120031@stu.untar.ac.id
}

\begin{abstract}
Fused Deposition Modelling (FDM) is a technology additive manufacture for modelling, prototyping, and production. This technology is one of the techniques used for 3D printers. Our focus is on studying, design machines fused deposition with 3D modeling and simulation with autodesk inventor and other design tools. Design is done by simulating the strength of the construction and then determine the components needed. We are making fused deposition modeling is intended as a prototype in order to understand how it works and how to innovate in the development of fused deposition modeling. The results of the design in the form of a fused depositon modeling that is able to create physical models.
\end{abstract}

Key words: 3D printer, Fused Deposition Modelling, Inventor, Prototyping.

\begin{abstract}
Abstrak: Fused Deposition Modelling (FDM) adalah sebuah teknologi additive manufacture yang digunakan untuk pemodelan, prototyping, dan produksi. Teknologi ini adalah salah satu teknik yang digunakan untuk 3D printer. Fokus kami adalah mempelajari, mendesain mesin fused deposition modelling dengan model 3D dan simulasi menggunakan autodesk inventor dan perangkat desain lainnya. Desain dan perancangan dilakukan dengan melakukan simulasi kekuatan kontruksi dan kemudian menentukan komponen-komponen yang dibutuhkan. Pembuatan fused deposition modelling ini bertujuan sebagai prototype agar dapat mengerti cara kerja dan cara melakukan inovasi pada pengembangan fused deposition modelling. Hasil perancangan berupa sebuah mesin fused depositon modelling yang mampu membuat model secara fisik.
\end{abstract}

Kata kunci: 3D printer, Fused Deposition Modelling, Inventor, Prototyping.

\section{PENDAHULUAN}

Industri manufaktur banyak menggunakan rapid prototyping untuk membuat prototype. Industri manufaktur menggunakan model CAD 3D tersebut kedalam gambar kerja 2D yang berisi informasi produk tersebut dalam proyeksi orthogonal dan isometri lalu memproduksi dengan teknik permesinan pada umumnya. Dengan perkembangan teknologi yang semakin pesat dalam pembuatan prototype tidak memakan banyak waktu dan biaya dapat terwujud dengan menggunakan mesin rapid prototyping yang dapat membuat prototype dalam waktu singkat dan biaya rendah. Additive manufacturing merupakan salah satu metode dalam teknik rapid prototyping, teknologi fused deposition modelling merupakan teknologi yang paling mudah diaplikasikan dalam additive manufacturing. Dalam makalah ini akan dibahas rancang bangun Mesin rapid prototyping berbasis fused deposition modelling yang mampu mencetak model 3 Dimensi secara fisik sebesar 150 x 150 x $150 \mathrm{~mm}$. Bahan filament yang digunakan dalam mesin ini menggunakan filament jenis PLA berdiameter $1,75 \mathrm{~mm}$.

FDM merupakan teknologi additive manufacture yang biasa digunakan untuk permodelan, prototyping, dan produksi. Sistem kerja FDM dengan filament dimasukan ke nozzle, nozzle dipanaskan untuk melelehkan plastik. Nozzle akan berjalan di atas meja sesuai dengan potongan geometrinya, plastik diekstrusi tipis untuk membuat setiap lapisannya, setelah itu plastik akan mengeras setelah dikeluarkan dari nozzle.

\section{METODE PENELITIAN}

Dalam proses Rancang Bangun Mesin Fused Deposition Modelling diperoleh satu model yang akan didesain, dan perancangan wujud dengan menggunakan Autodesk Inventor. Peralatan yang digunakan pada perancangan ini adalah personal computer untuk melakukan desain dan software Autodesk Inventor untuk melakukan perancangan wujud dari konsep desain alat yang dibuat. 


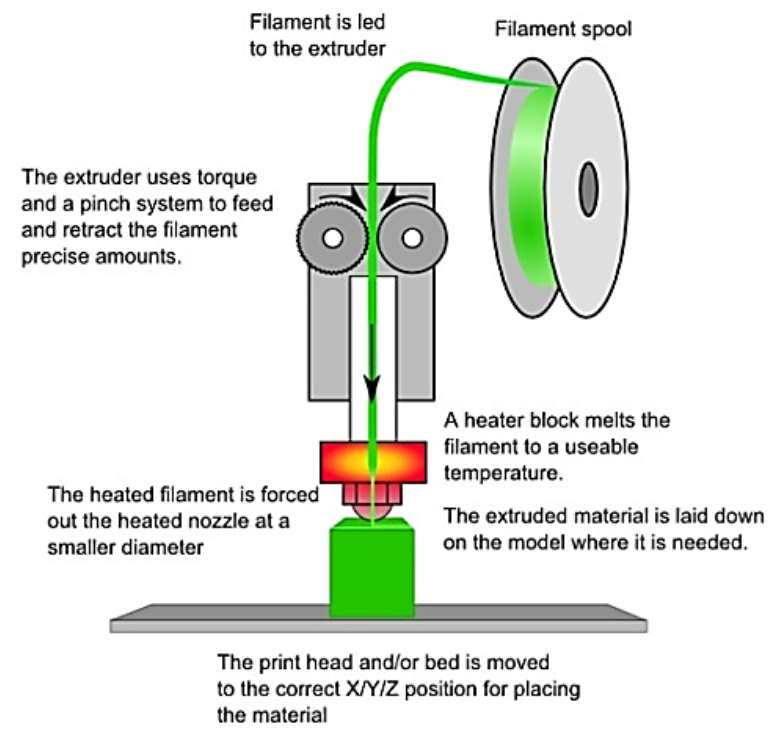

Gambar 1. Proses extrusi filament fused deposition modelling
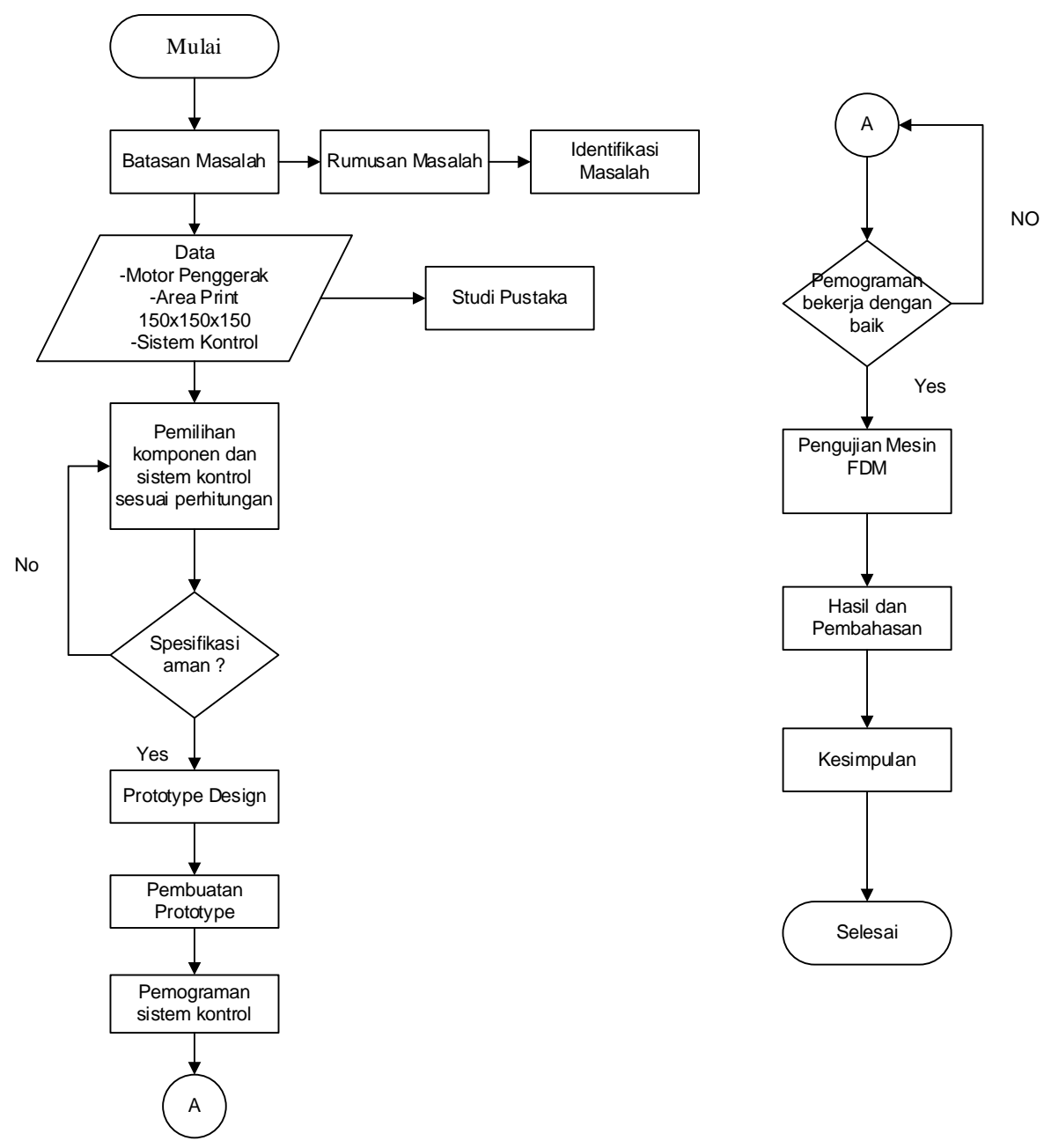

Gambar 2. Diagram alir metode perancangan

\section{Desain Lead Screw}

Pitch atau jarak lead screw adalah $2 \mathrm{~mm}$ dengan panjang dari motor ke limit switch $200 \mathrm{~mm}$. maka jarak translasi dapat dihitung: 


$$
\begin{gathered}
\text { Jarak Translasi }=\frac{\text { perpindahan angular } \times \text { pitch }}{\text { besar sudut satu lingkaran penuh }} \\
\text { Jarak Translasi }=\frac{1.8^{\circ} \times 2 \mathrm{~mm}}{360^{\circ}}=0,01 \mathrm{~mm} \\
\text { Jarak Translasi }=\frac{1000 \times 0,01 \mathrm{~mm}}{\frac{1}{16} \text { Step }}=0,625 \text { mikron }
\end{gathered}
$$

\section{Desain Sabuk Penggerak}

Standar lebar timing belt $=6 \mathrm{~mm}$ MXL dengan jarak pitch $2 \mathrm{~mm}$ Jarak translasi pada belt:

$$
\begin{gathered}
\text { Jarak Translasi }=\frac{\text { Pulley circumference } x \text { perpindahan angular }}{\text { besar sudut satu lingkaran penuh }} \\
\text { Jarak Translasi }=\frac{40 \mathrm{~mm} \times 1.8^{\circ}}{360^{\circ}}=0,2 \mathrm{~mm} \\
\text { Jarak Translasi }=\frac{1000 \times 0,2 \mathrm{~mm}}{\frac{1}{16} \mathrm{step}}=12,5 \text { mikron }
\end{gathered}
$$

3. Desain Linear Guideway
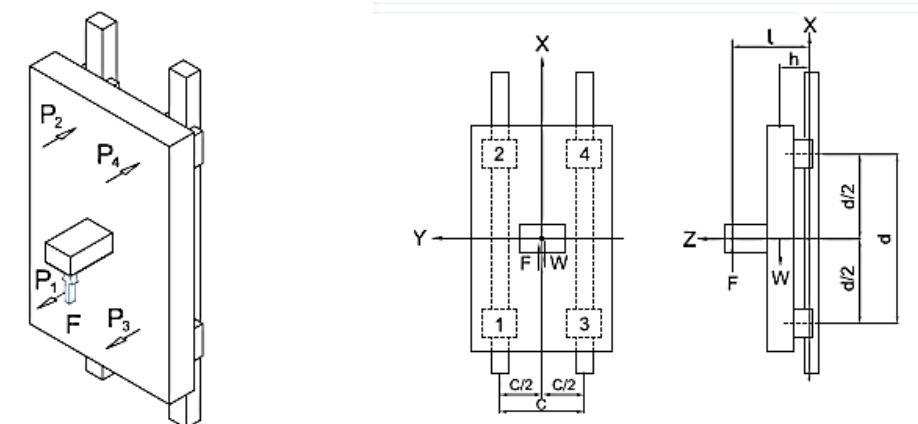

$$
P_{1} \sim P_{4}=-\frac{W \cdot h}{2 d}+\frac{F \cdot l}{2 d}
$$

Gambar 3. Rumus Menghitung Linear Guideway

Diketahui : $\mathrm{W}=0,054 \mathrm{kN}$

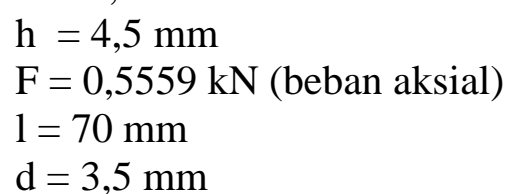

$$
\begin{gathered}
P_{1}-P_{4}=-\frac{W \cdot h}{2 d}+\frac{F \cdot l}{2 d} \\
P_{1}-P_{4}=-\frac{0,054 \cdot 4,5}{2.3,5}+\frac{0,5559 \cdot 70}{2.3,5}=\frac{-0,243+38,9}{7}=5,5 \mathrm{kN}
\end{gathered}
$$

Faktor statis keamanan :

Diketahui : $\mathrm{Co}=5,66 \mathrm{kN}$

$$
\mathrm{P}=5,5 \mathrm{kN}
$$

$$
\begin{gathered}
f_{s l}=\frac{C_{o}}{P} \\
f_{s l}=\frac{5,66}{5,5}=1,02 \mathrm{kN}
\end{gathered}
$$

4. Kekuatan Rangka

Simulasi defleksi pada kontruksi yang diberi beban sebesar $1 \mathrm{~kg}$ maka didapat defleksi maksimum sebesar $0,7 \mathrm{~mm}$. 


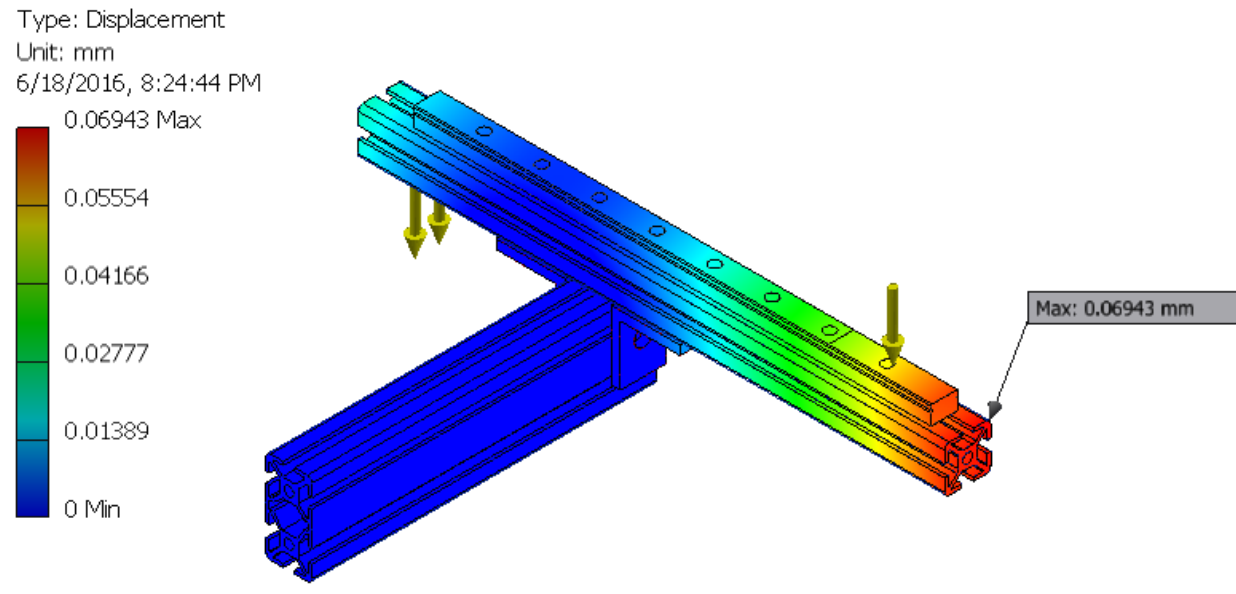

Gambar 4. Defleksi Maksimum

\section{Hasil Rancangan Mesin Rapid Prototype}

Rancangan kontruksi mesin rapid prototype sebesar 385 x 380 x 370 mm. Sistem penggerak yang digunakan motor stepper NEMA 17 memiliki resolusi 200 step per revolution dan perpindahan angular sebesar $1,8^{\circ}$.

Mesin Rapid Prototype mempunyai 3 sumbu gerak yaitu sumbu X, Y, dan Z. Penggerak sumbu $\mathrm{Z}$ menggunakan lead screw diameter $9 \mathrm{~mm}$ dan pitch $2 \mathrm{~mm}$. sumbu XY menggunakan sabuk penggerak pitch $2 \mathrm{~mm}$ dan lebar pitch $6 \mathrm{~mm}$.

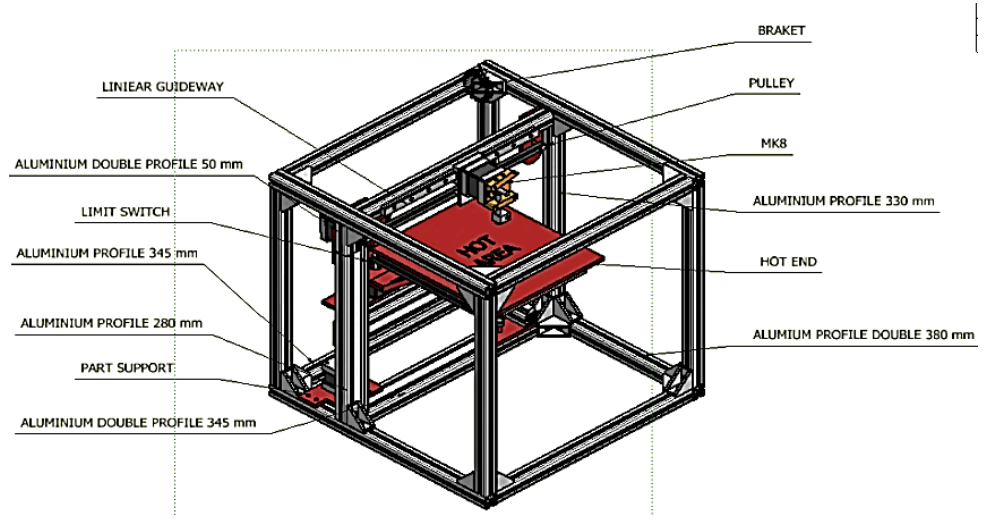

(A) Isometric Depan

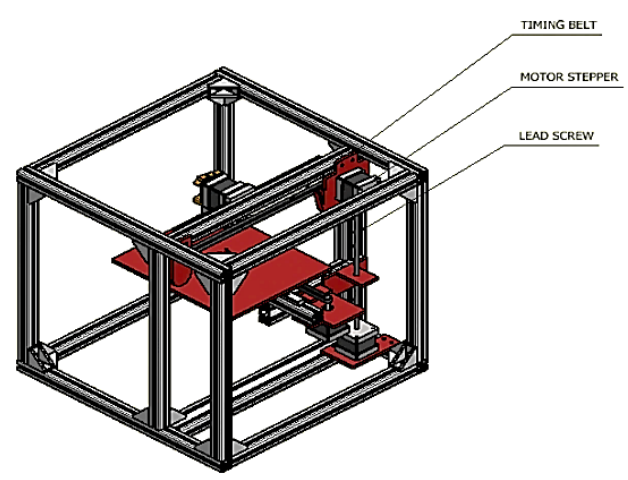

(B) Isometric Belakang

Gambar 5. Hasil Rancangan Mesin Rapid Prototype

\section{HASIL DAN PEMBAHASAN}

Langkah pengujian adalah melakukan pengujian gerak sumbu pada mesin fused deposition modeling. 
Tabel 1. Pengujian Mesin Fused Deposition Modelling

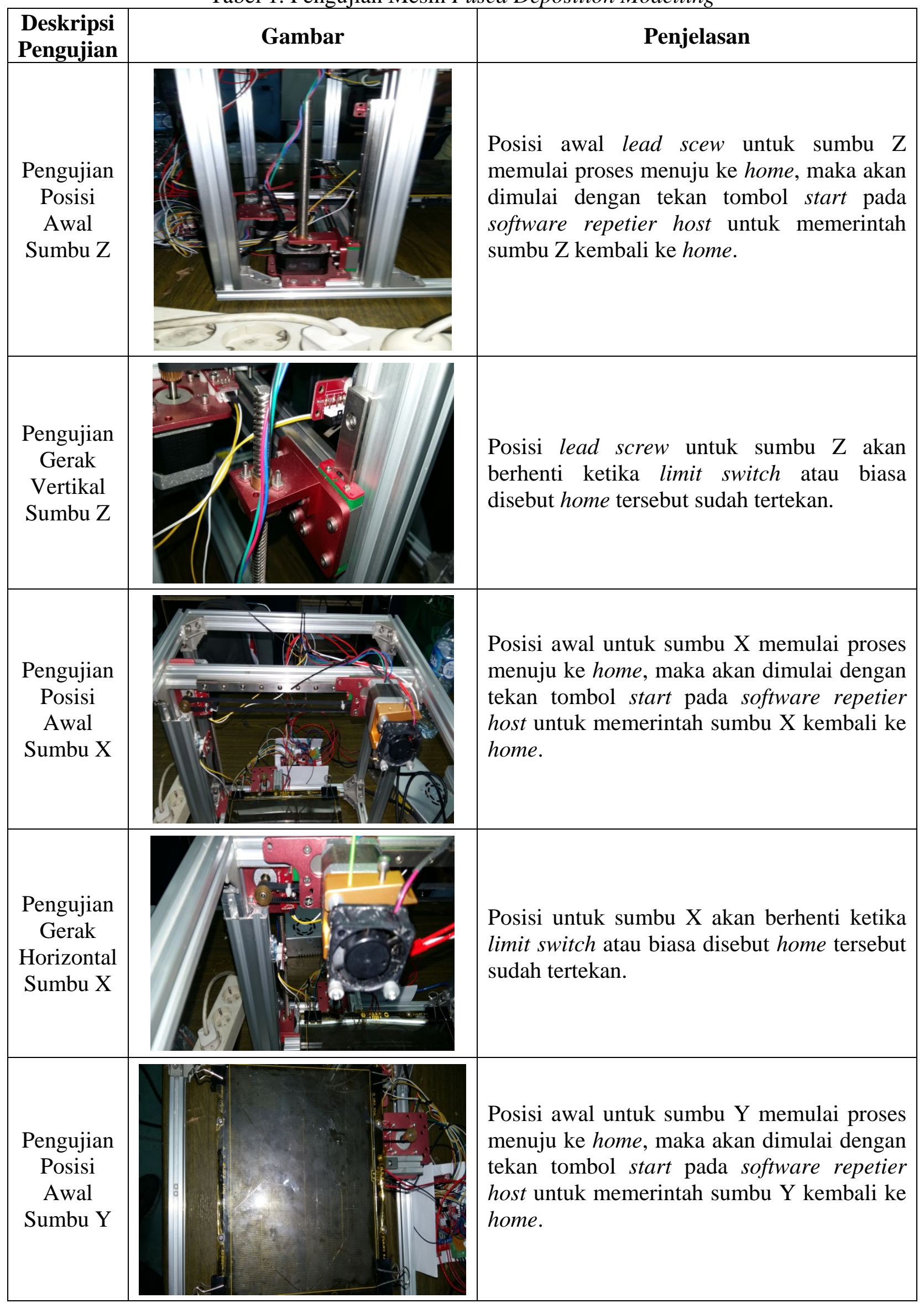


Tabel 1. Pengujian Mesin Fused Deposition Modelling

\begin{tabular}{|c|c|c|}
\hline $\begin{array}{c}\text { Deskripsi } \\
\text { Pengujian }\end{array}$ & Gambar & \multicolumn{1}{c|}{ Penjelasan } \\
\hline Pengujian & & \\
Gerak & &
\end{tabular}

1. Pengujian penyimpangan sumbu gerak:

Dalam pengujian ini dilakukan pergerakan sumbu X dan Y masing-masing sejauh $100 \mathrm{~mm}$ sehingga gerakan XY tersebut berbentuk bujursangkar. Pada ujung extruder dipasangkan probe / pena yang digoreskan pada kertas milimeter, lintasan hasil uji terdapat penyimpangan sumbu $\mathrm{X}-\mathrm{X}^{\prime}$ $=0,4^{\circ}$ dan $Y-Y^{\prime}=2,9^{\circ}$.

Sumbu X dan Y

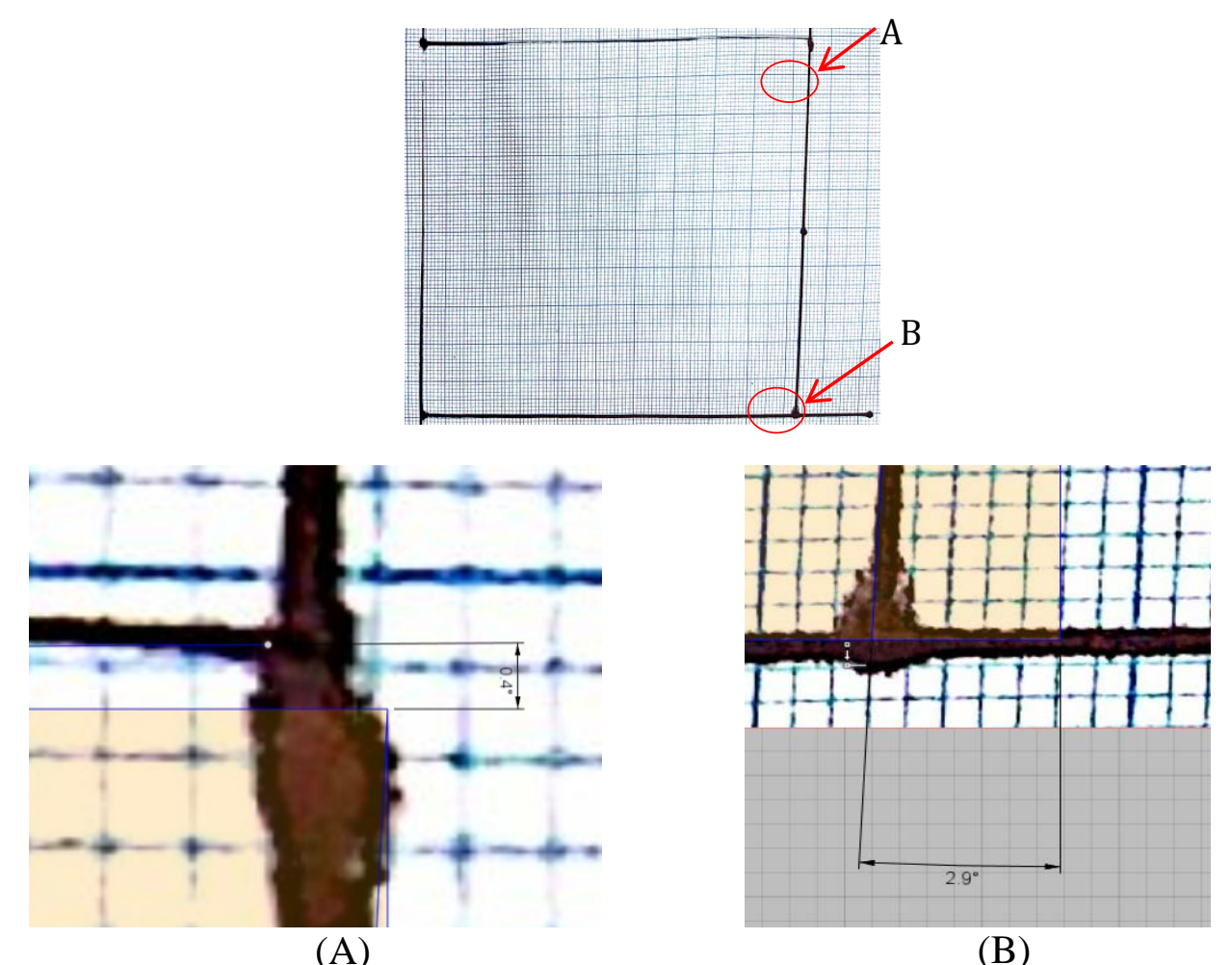

Sumbu X-X' Kemiringan $=0,4^{\circ} \quad$ Sumbu Y-Y' Kemiringan $=2.9^{\circ}$

Gambar 6. Pengujian Sumbu Gerak XY 
Pengujian gerakan melingkar, dalam pengujian ini sumbu gerak XY diperintahkan untuk bergerak membentuk lingkaran berdiameter $150 \mathrm{~mm}$ dan hasil yang diperoleh berbentuk oval. Pada ujung extruder dipasangkan probe / pena yang digoreskan pada kertas milimeter, lintasan hasil uji terdapat penyimpangan sumbu $\mathrm{X}-\mathrm{X}^{\prime}=14,396 \mathrm{~mm}$ dan $\mathrm{Y}-\mathrm{Y}^{\prime}=13,948 \mathrm{~mm}$.

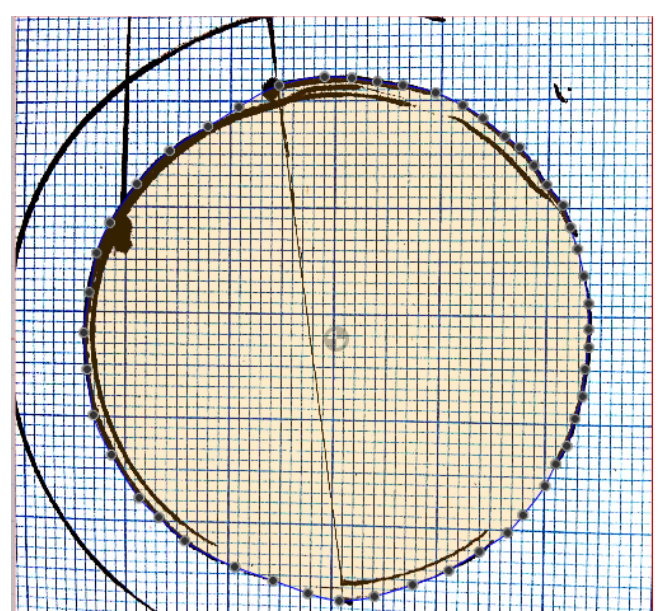

(A)

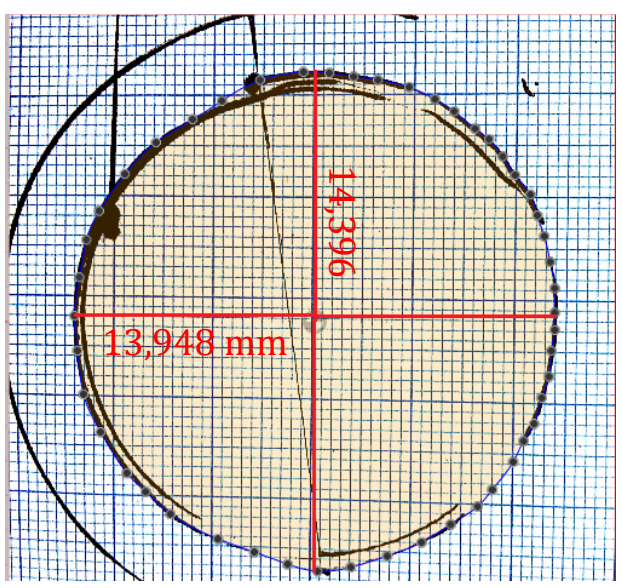

(B)

2. Pengujian Mencetak Model 3Dimensi

Gambar 7. Lingkaran

Dalam pengujian ini mesin fused deposition modelling diuji mencetak model 3Dimensi primitive shape.

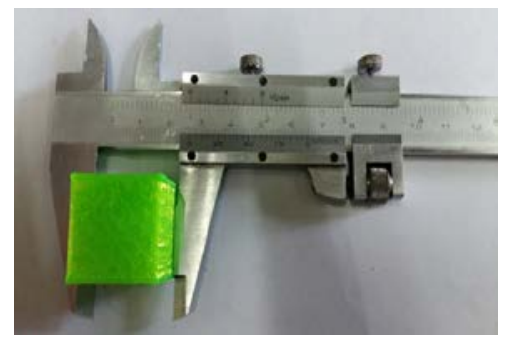

(A) Kubus

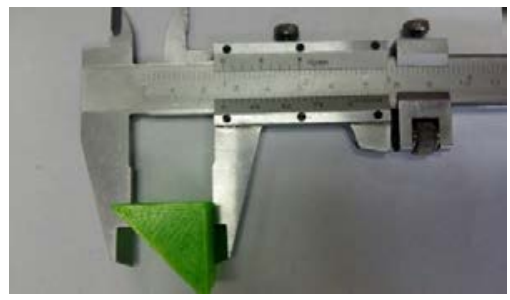

(C) Prisma Segitiga

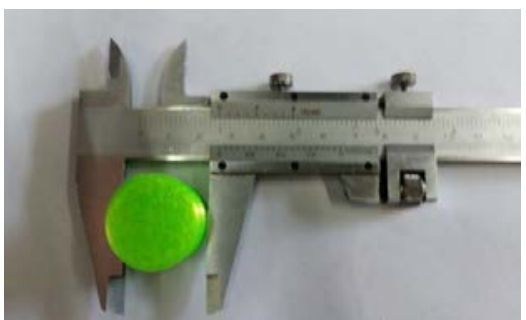

(B) Tabung

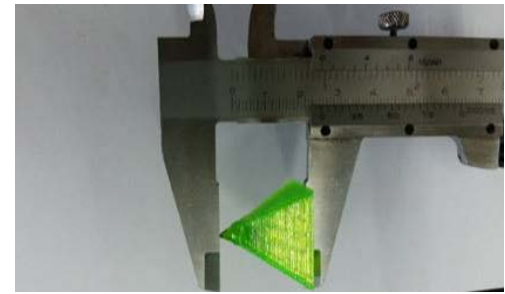

(D) Piramida

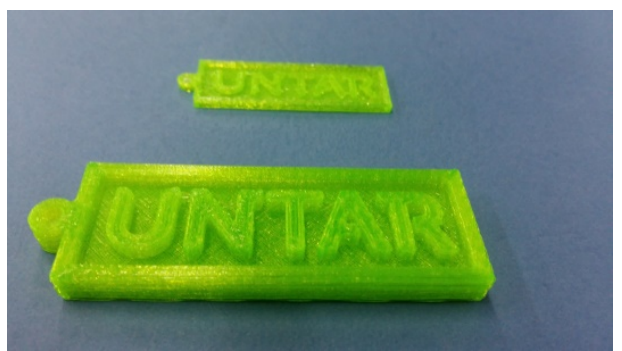

(E) Pencetakan Logo UNTAR

Gambar 8. Model 3Dimensi Primitive Shape 


\section{KESIMPULAN}

Berdasarkan penelitian yang dilakukan maka dapat diambil kesimpulan sebagai berikut :

a. Pemilihan komponen dapat bekerja dengan baik sesuai seperti yang direncanakan dan dirancang.

b. Simulasi defleksi maksimum pada aluminium profile yang terdapat beban pada meja sebesar $0,07 \mathrm{~mm}$.

c. Dapat mencetak model 3Dimensi secara fisik sebesar 150 x 150 x $150 \mathrm{~mm}$.

d. Pengujian sumbu gerak terjadi penyimpangan pada sumbu $\mathrm{X}-\mathrm{X}^{\prime}=0,4^{\circ}$ dan $\mathrm{Y}-\mathrm{Y}^{\prime}=2 \cdot 9^{\circ}$.

\section{DAFTAR PUSTAKA}

[1] Ahmad Rifai, Usep Setia Gunawan dan Indarzah Masbatin Putra, Nopember 2011, “ Rancang Bangun Pengaturan Gerak Motor Stepper Untuk Peralatan Brakiterapi”, Jurnal Perangkat Nuklir, Volume 05, Nomor 02.

[2] Evans, Brians. 2012. Practical 3D Printers . Springer Science Business Media New York, 233 Spring Street.

[3] Eggert, Rudolph J. 2005. Engineering Design. Upper Saddle River : Pearson Prentince Hall.

[4] Hiwin Technologies Corp, 2008, Linear Guideway Technical Information, Hiwin Technologies Corp, Taiwan.

[5] Hiwin Technologies Corp, 2008, Ballscrews Technical Information, Hiwin Technologies Corp, Taiwan.

[6] Iman Mujiarto, Desember 2005, “ Sifat dan Karakteristik Material Plastik dan Bahan Additif”, Traksi, Volume 03, Nomor 02.

[7] Khurmi.,J.K.Gupta, 2005. A Text Book Of Machine Design. Eurasia Publishing Hous (Pvt) LTD Ram Nagor. New Delhi.

[8] Kholil Ahmad, 2008. Pengembangan Laser Trajectory Proses Rapid Prototyping untuk Produk Berkontur dan Prismatik, Universitas Indonesia.

[9] Sajima, Deddy Hasnurrofig dan Sudaryadi, September 2012, “ Rancang Bangun Screw Feeder Sebagai Perangkat Dukung Peleburan Konsentrat Zirkon”, Prosiding Seminar Penelitian dan Pengelolaan Perangkat Nuklir, Yogyakarta.

[10] Yong-Sub Yi, Yoon Young Kim, Jae Seok Choi, Jeonghoon Yoo, Dong Jin Lee, Suk Won Lee dan Sung Jin Lee, July 2007, “ Dynamic analysis of a linear motion guide having rolling elements for precision positioning divices”, Journal of Mechanical Science and Technology, Volume 22, hal 50-60. 